\title{
Research article \\ A study of metabolic syndrome and its association with demographic, anthropometric and biochemical parameters
}

\author{
Jaseem T., 1, Rebecca Abraham², Dinesh Kumar M. K. ${ }^{3}$, Beena Kumari², Sangeetha V. Joice ${ }^{2}$ \\ ${ }^{1}$ Department of Biochemistry, Manipal TATA Medical College, Manipal Academy of Higher Education, Manipal, India \\ ${ }^{2}$ Department of Biochemistry, ${ }^{3}$ Department of Psychiatry, Malabar Medical College, Ulliyeri, Kozhikode, Kerala, India
}

(Received: October $2020 \quad$ Revised: September $2021 \quad$ Accepted: September 2021)

Corresponding author: Jaseem T. Email: Jaseem.t@manipal.edu

\begin{abstract}
Introduction and Aim: Metabolic syndrome (Mets) is a constellation of interrelated metabolic rearrangements like obesity, hypertension, hyperglycemia, and dyslipidemia which can predispose to a greater risk of developing cardiovascular events. This study is aimed to assess the demographic profile of Mets in rural Calicut of Southern India.

Materials and Methods: This study was carried out over a period of one year in a tertiary care teaching hospital. Anthropometric measurements (height, weight, waist circumference) and blood pressure were taken. Fasting blood samples were analyzed to measure glucose, triglyceride, high-density lipoprotein cholesterol and thyroid-stimulating hormone.
\end{abstract}

Results: Out of the randomly selected 650 patients, 347 (53.3\%) were males and 303(46.6\%) were females, adopting the National Cholesterol Education Program Adult Treatment Panel III criteria (NCEP ATP III) Mets was more prevalent in females than in men $(34.32 \% \mathrm{v} / \mathrm{s} 14.12 \%)$. Maximum numbers of Mets cases were in the age range of 50-59 years followed by 40-49 years. Among the 153 cases of Mets, decreased high-density lipoprotein was the most common (99\%) among females and hyperglycemia (51\%) among males.

Conclusion: The prevalence of MetS in the <50 years' age group is rapidly increasing. It's high time to be more active physically before the onset of any fatal cardiovascular events.

Keywords: Dyslipidemia; hypertension; metabolic syndrome; obesity; TSH.

\section{INTRODUCTION}

M etabolic syndrome (Mets) is a cluster of biological factors characterized by abdominal obesity, dyslipidemia, hypertension and type 2 diabetes mellitus. It directly increases the risk of several diseases such as cardiovascular diseases, Type 2 diabetes mellitus, chronic kidney diseases, fatty liver, and several types of cancer. Urbanization, surplus energy intake, increased obesity and sedentary life habits have all contributed to Mets being a major and escalating public health challenge. Many studies in urban India have reported a high prevalence of Mets. However, there is a paucity of data from rural areas of India. The present study was therefore undertaken to (a) assess the presence of Mets in a rural region of Kozhikode district, Kerala, and (b) to quantify factors significantly contributing to its presence.

\section{MATERIALS AND METHODS}

This is a retrospective hospital-based study, apparently healthy subjects aged $18-80$ years $(n=650$ subjects) both male and female who attended the "Sampoorna Arogya Project", - a health scheme of Malabar Medical College Hospital and Research Centre formed part of the study group. Mets and its five criteria were classified according to the parameters established by modified NCEP ATP III
(1). Subjects were categorized as having Mets if they had more than 3 of these criteria namely waist circumference $(\mathrm{WC})>102 \mathrm{~cm}$ in men and $>88 \mathrm{~cm}$ in women, blood pressure (BP) $\geq 130 / \geq 85 \mathrm{mmHg}$, triglycerides (TG) $\geq 150 \mathrm{mg} / \mathrm{dl}$, HDL cholesterol (HDL-C) $<40 \mathrm{mg} / \mathrm{dl}$ in males and $<50 \mathrm{mg} / \mathrm{dl}$ in females, and fasting glucose $\geq 110 \mathrm{mg} / \mathrm{dl}$ or use of medication for hyperglycaemia.

Basic demographic information and physical data including height, weight, waist circumference, systolic and diastolic blood pressure were collected. BMI was calculated. The lab investigations included fasting and postprandial blood sugar levels, lipid profile and measurement of thyroid-stimulating hormone (TSH) levels. All patients gave written consent and the study was approved by the ethical committee of Malabar Medical College Hospital \& Research Centre. Patients with a history of alcoholic liver disease, renal failure, tuberculosis, hepatitis B or $\mathrm{C}$ and those on lipid-lowering drugs were excluded from the study.

\section{Serum analysis}

Blood samples were collected by anterior cubital fossa venepuncture. They were requested to fast for $12 \mathrm{hrs}$ before their blood is drawn. TSH: Levels of TSH were estimated quantitatively using the Enzyme-Linked Fluorescent Assay (ELFA) technique on the 
Minividas Analyzer (Biomerieux, France). The analytical detection limit was $0.05 \mu \mathrm{IU} / \mathrm{ml}$, the laboratory's reference values for $\mathrm{TSH}=0.25$. -5.0 $\mu \mathrm{IU} / \mathrm{ml}$.

Glucose was estimated by glucose oxidase peroxidase method (GOD-POD). Cholesterol was estimated by the cholesterol oxidase peroxidase method (CHODPAP). LDL cholesterol was calculated using Friedewald's formula, LDL cholesterol $=$ Total cholesterol-(triglycerides/5 + HDL). Triglycerides were estimated by the glycerol phosphate oxidase peroxidase method (GPO-PAP). HDL cholesterol was estimated by a direct method. The estimation of the above parameters was carried out on the fully automated analyser EM 360 (Transasia bio medicals Ltd, Erba Manheim, Germany).

\section{Statistical analysis}

The data will be presented as mean $\pm \mathrm{SD}$ and analysed using one-way ANOVA followed by the student t-test. $\mathrm{P}<0.05$ will be considered as significant.

\section{RESULTS}

Out of the 650 subjects included in this study $347(53.3 \%)$ were males and 303(46.6\%) were females. The prevalence of Mets in the community was $23.5 \%$. Mets was significantly higher in females $(34.32 \%)$ as compared to males $14.12 \%(\mathrm{p}<0.001)$. This gender-wise prevalence was also noted across different age groups (Table 1). Significantly higher $(p<0.001)$ rate of Mets was seen in the older age group in both males and females. The percentage of males with Mets increased from 8\% in the age group 30-39 years to $22 \%$ at $60-69$ years. A similar trend was seen in females with $16 \%$ in the age group 30-39 years and peaking at $63 \%$ in the age group 60-69 years (fig 1). Interestingly the number of males and female subjects with Mets in the age group 20-29 years was low and almost identical (4/29 in males and 5/22 in females). Overall only $9 / 51$ subjects had Mets in this age group (Table 1).

Table 1: Age-group specific prevalence of the metabolic syndrome

\begin{tabular}{|c|c|c|c|c|c|}
\hline Age group & Total (M/F) & $\begin{array}{c}\text { Males with } \\
\text { Mets (n) }\end{array}$ & $\begin{array}{c}\text { Female } \\
\text { with Mets (n) }\end{array}$ & Overall(n) & Percentage \\
\hline 20-29 Years & $51(29 / 22)$ & 4 & 5 & 9 & \multirow{2}{*}{ Males $14.12 \%$} \\
\hline 30-39 Years & $168(75 / 93)$ & 6 & 15 & 21 & \\
\hline 40-49 Years & $171(107 / 64)$ & 15 & 21 & 36 & \\
\hline 50-59 Years & $165(83 / 82)$ & 11 & 37 & 48 & \multirow{2}{*}{ Females 34.32\% } \\
\cline { 1 - 4 } 60-69 Years & $76(41 / 35)$ & 9 & 22 & 31 & \\
\cline { 1 - 4 }$\geq 70$ Years & $19(12 / 7)$ & 4 & 4 & 8 & \multirow{2}{*}{$23.50 \%$} \\
\hline Total & $650(347 / 303)$ & 49 & 104 & 153 & \\
\hline
\end{tabular}

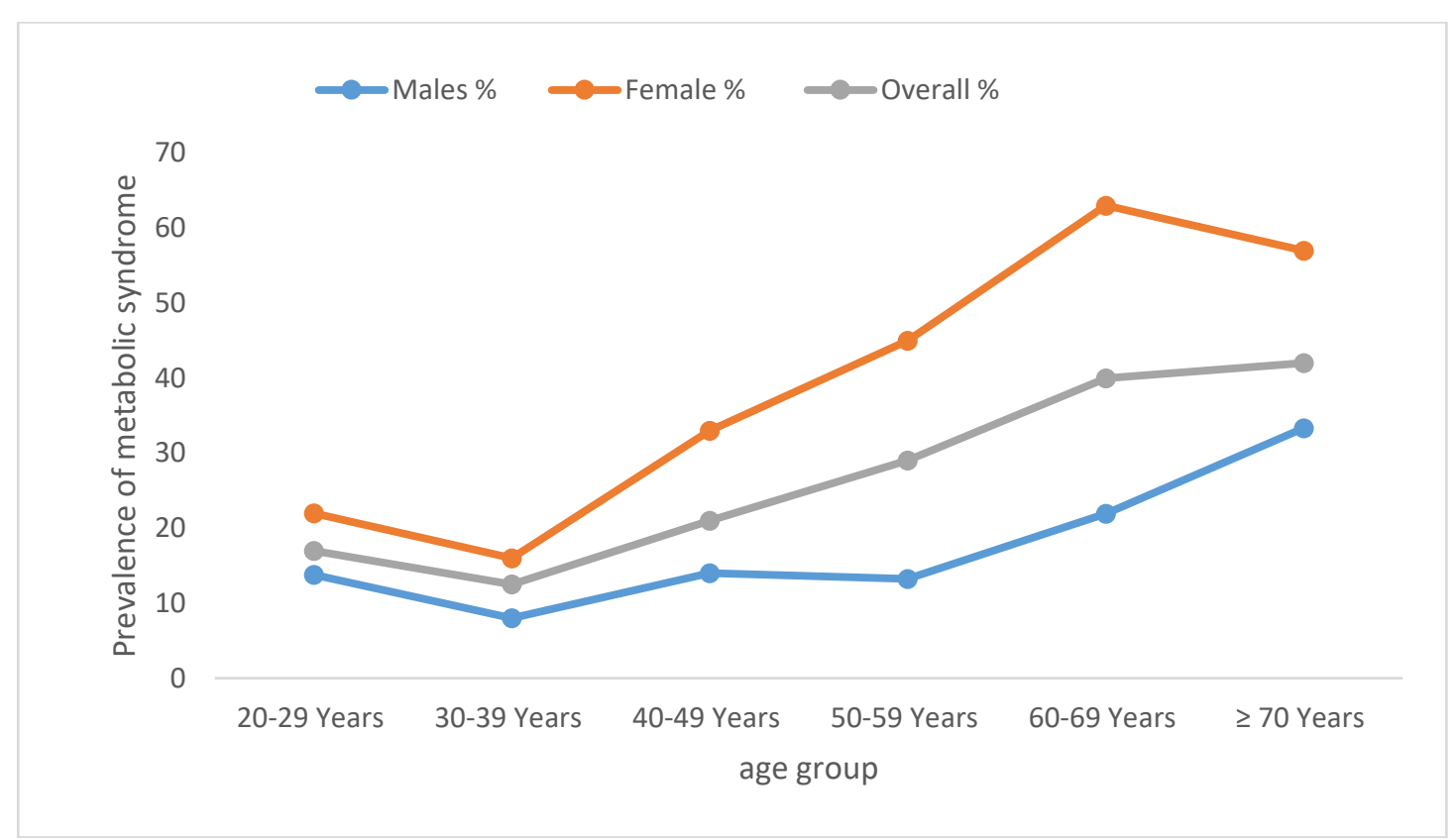

Fig. 1: Age-group specific prevalence of the metabolic syndrome

\section{Demographic data}

The demographic characteristics are seen in (Table 2). The mean of waist circumference $(\mathrm{P}<0.001)$, fasting blood sugar $(\mathrm{P}<0.050)$, triglycerides $(\mathrm{P}<0.001)$ were higher in males as compared to females. On the other hand, TSH $(\mathrm{P}<0.001)$ and systolic blood pressure $(\mathrm{P}<0.007)$ were observed in females. 
Table 2: Mean of demographic parameters

\begin{tabular}{|c|c|c|c|c|}
\hline & Total & M & F & P value \\
\hline N & 650 & $\mathrm{M}=347$ & $\mathrm{~F}=303$ & \\
\hline Age & $47 \pm 12$ & $47 \pm 12$ & $46 \pm 12$ & 0.539 \\
\hline Waist & $86 \pm 10$ & $87 \pm 10$ & $83 \pm 10$ & 0.001 \\
\hline SBP & $127 \pm 14$ & $126 \pm 10$ & $129 \pm 10$ & 0.007 \\
\hline DBP & $84 \pm 9$ & $83+10$ & $84+10$ & 0.080 \\
\hline FBS & $106 \pm 31$ & $108 \pm 32$ & $104 \pm 31$ & 0.050 \\
\hline TG & $114 \pm 56$ & $129 \pm 68$ & $96 \pm 31$ & 0.001 \\
\hline HDL & $43 \pm 3$ & $43 \pm 2$ & $44 \pm 3$ & 0.137 \\
\hline TSH & $2.6 \pm 5$ & $1.8 \pm 1.8$ & $3.4 \pm 6.7$ & 0.001 \\
\hline BMI & $24 \pm 4$ & $24 \pm 4$ & $24 \pm 4$ & 0.074 \\
\hline
\end{tabular}

Table 3: Occupation and metabolic syndrome

\begin{tabular}{|c|c|c|c|}
\hline Occupation & N & Mets & Percent (\%) \\
\hline Farmer & 40 & 9 & 22.5 \\
\hline Business & 71 & 8 & 11.3 \\
\hline Housewife & 279 & 99 & 35.5 \\
\hline Labourer & 101 & 10 & 9.9 \\
\hline Teacher & 28 & 6 & 21.4 \\
\hline Driver & 27 & 1 & 3.7 \\
\hline Govt. Service & 33 & 4 & 12.1 \\
\hline Ex-service & 27 & 5 & 18.5 \\
\hline Others & 44 & 11 & 25.0 \\
\hline TOTAL & 650 & 153 & 23.5 \\
\hline
\end{tabular}

\section{Occupation and metabolic syndrome}

On comparing occupation and Mets, it was observed that $35.5 \%$ of housewives had Mets (Table 3).

\section{Economic status and diet in metabolic syndrome}

Mets was significantly higher in subjects of the APL group as compared to the BPL group $(p<0.050)$ (Table 4). However, diet (vegetarian v/s non vegetarian) did not significantly affect the prevalence of Mets (Table 5).

Table 4: Economic status and metabolic syndrome

\begin{tabular}{|c|c|c|c|c|}
\hline Economic status & N & Mets & Percent (\%) & \multirow{2}{*}{$\mathbf{P}<\mathbf{0 . 0 5 0}$} \\
\cline { 1 - 4 } APL & 544 & 135 & 24.8 & \\
\hline BPL & 106 & 18 & 17.0 & \\
\hline Total & 650 & 153 & 23.5 & \\
\hline
\end{tabular}

Table 5: Diet and metabolic syndrome

\begin{tabular}{|c|c|c|c|}
\hline Diet & $\mathbf{N}$ & Mets & Percent (\%) \\
\hline Veg & 10 & 2 & 20.0 \\
\hline Non veg & 640 & 151 & 23.6 \\
\hline Total & 650 & 153 & 23.5 \\
\hline
\end{tabular}

\section{Components of the metabolic syndrome}

The prevalence of components of metabolic syndrome amongst males and females at different age groups is shown in (Table 6). it is evident that a higher prevalence of all these components namely altered waist circumference, blood pressure, fasting blood sugar, HDL, TG and BMI are seen between the age of 30 and 60 years.

The percentage distribution of individual components of Mets amongst the study subjects (Fig.2). Overall elevated blood sugar (47\%) was the common abnormality observed and elevated blood pressure was the least common 18\%. low HDL (99\%) was a common abnormality amongst women followed by elevated waist circumference $(62 \%)$. Elevated TG (29\%) was more common amongst male subjects as opposed to women (8\%). Low HDL (10\%) was the least common abnormality amongst males. (Fig.2)

\section{Diabetes and metabolic syndrome}

In the present study (15.6\%) of males with Mets had Impaired glucose and $21.1 \%$ had diabetes. $26.5 \%$ of females with MetS had impaired glucose $26.6 \%$ had diabetes. The overall prevalence of diabetes associated with MetS was $47.8 \%$ and that of IFG was $42.2 \%$ (Table 7). 


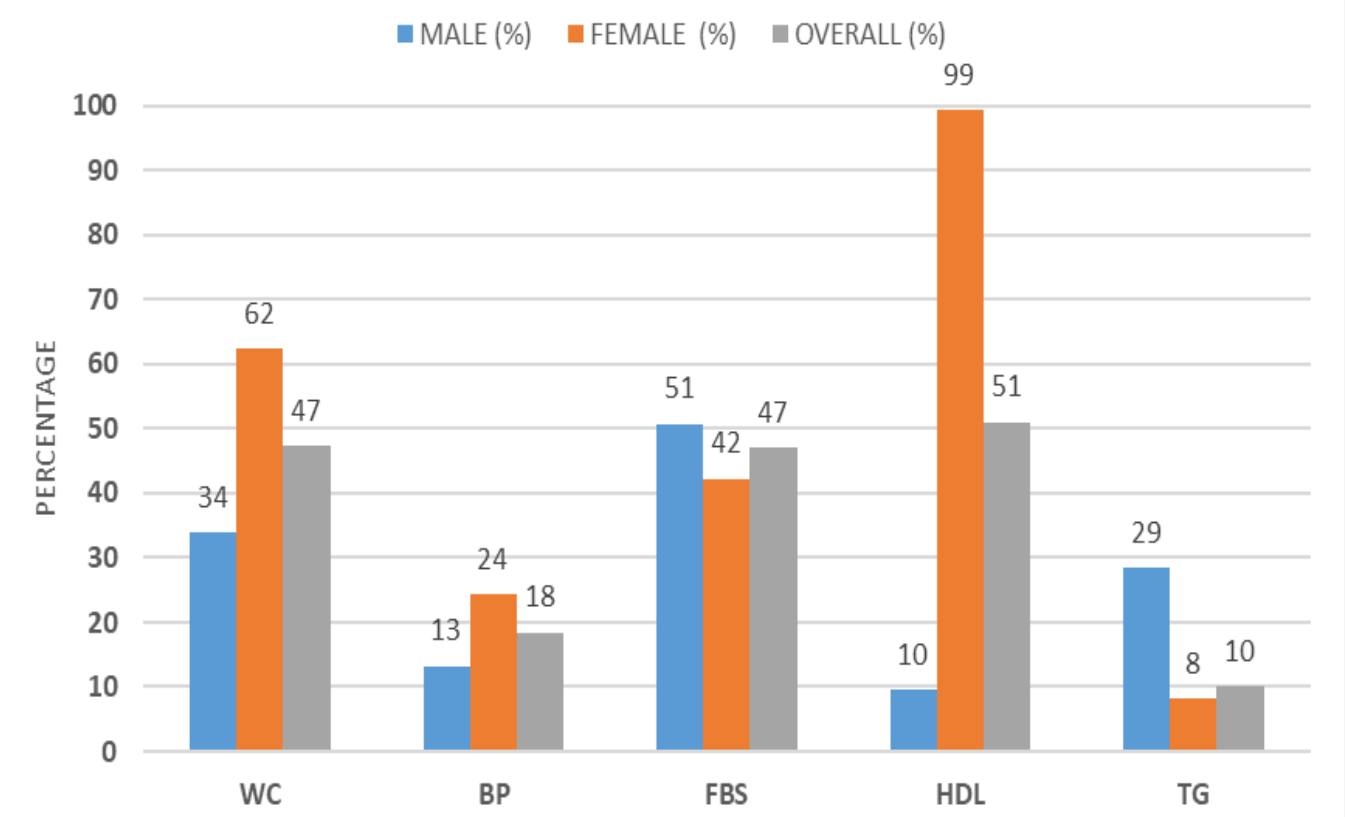

Fig. 2: Percentage distribution Individual components of metabolic syndrome in the study subjects. TG = Triglycerides; HDL = High-density lipoprotein; FBS = Fasting Blood sugar; BP = Blood pressure.

Table 6: Age-group specific prevalence of various components of the metabolic syndrome

\begin{tabular}{|c|c|c|c|c|c|c|c|c|c|c|c|c|}
\hline \multirow[t]{2}{*}{ Age Group } & \multicolumn{2}{|c|}{$\begin{array}{c}\mathrm{WC} \\
>90 / 80 \mathrm{~cm} \\
\end{array}$} & \multicolumn{2}{|c|}{$\begin{array}{c}\mathrm{SBP} / \mathrm{DBP} \geq \\
130 / 85 \mathrm{~mm} \mathrm{Hg}\end{array}$} & \multicolumn{2}{|c|}{$\begin{array}{c}\mathrm{FBS} \geq 100 \mathrm{mg} / \mathrm{dl} \\
\text { or DM }\end{array}$} & \multicolumn{2}{|c|}{$\begin{array}{c}\mathrm{HDL} \\
<40 / 50 \mathrm{mg} / \mathrm{dl} \\
\end{array}$} & \multicolumn{2}{|c|}{$\begin{array}{c}\text { TG } \\
\geq 150 \mathrm{mg} / \mathrm{dl} \\
\end{array}$} & \multicolumn{2}{|c|}{$\mathrm{BMI} \geq 30$} \\
\hline & $\mathrm{M}$ & $\mathrm{F}$ & $\mathrm{M}$ & $\mathrm{F}$ & $\mathrm{M}$ & $\mathrm{F}$ & $\mathrm{M}$ & $\mathrm{F}$ & $\mathrm{M}$ & $\mathrm{F}$ & $\mathrm{M}$ & F \\
\hline $\mathrm{N}$ & 347 & 303 & 347 & 303 & 347 & 303 & 347 & 303 & 347 & 303 & 347 & 303 \\
\hline $20-29$ & 6 & 12 & 2 & 1 & 12 & 6 & 1 & 22 & 9 & 1 & 2 & 1 \\
\hline $30-39$ & 20 & 56 & 9 & 10 & 35 & 26 & 1 & 92 & 29 & 4 & 6 & 4 \\
\hline $40-49$ & 39 & 44 & 15 & 12 & 54 & 24 & 6 & 64 & 31 & 4 & 9 & 6 \\
\hline $50-59$ & 31 & 56 & 12 & 30 & 46 & 40 & 7 & 81 & 19 & 11 & 7 & 4 \\
\hline $60-69$ & 16 & 17 & 5 & 17 & 20 & 25 & 15 & 35 & 10 & 5 & 1 & 1 \\
\hline$\geq 70$ & 7 & 4 & 3 & 4 & 9 & 7 & 3 & 7 & 1 & 0 & 1 & 1 \\
\hline Total (n) & 119 & 189 & 46 & 74 & 176 & 128 & 33 & 301 & 99 & 25 & 26 & 17 \\
\hline Percentage (\%) & 34 & 62 & 13 & 24 & 51 & 42 & 10 & 99 & 29 & 8 & 7 & 6 \\
\hline Over all (n) & \multicolumn{2}{|c|}{308} & \multicolumn{2}{|c|}{120} & \multicolumn{2}{|c|}{304} & \multicolumn{2}{|c|}{334} & \multicolumn{2}{|c|}{124} & \multicolumn{2}{|c|}{13} \\
\hline Overall (\%) & \multicolumn{2}{|c|}{47} & \multicolumn{2}{|c|}{18} & \multicolumn{2}{|c|}{47} & \multicolumn{2}{|c|}{51} & \multicolumn{2}{|c|}{19} & \multicolumn{2}{|c|}{2} \\
\hline
\end{tabular}

Table 7: Diabetes and metabolic syndrome

\begin{tabular}{|c|c|c|c|c|c|}
\hline FBS $(\mathrm{mg} / \mathrm{dl})$ & $\mathrm{N}$ & Mets + Male & Mets + Female & Total $(\mathrm{M}+\mathrm{F})$ & Percent $(\%)$ \\
\hline$<109$ & 496 & 20 & 63 & 83 & 16.7 \\
\hline $110-126$ & 64 & $10(15.6 \%)$ & $17(26.5 \%)$ & 27 & 42.2 \\
\hline$>126$ & 90 & $19(21.1 \%)$ & $24(26.6)$ & 43 & 47.8 \\
\hline TOTAL & 650 & 49 & 104 & 153 & 23.5 \\
\hline
\end{tabular}

\section{Thyroid state and metabolic syndrome}

The overall prevalence of thyroid dysfunction was $16 \%(103 / 650)$ of which $86 \% \quad(89 / 103)$ were hypothyroid. A higher percentage of hypothyroidism
(73 \%, $\mathrm{n}=65)$ was observed in women. Mets was observed in $27 \%(24 / 89)$ of hypothyroid subjects of which $79 \%$ (19/24) were females (Table 8).

Table 8: Components of metabolic syndrome among different thyroid dysfunction group( $\mathrm{n}=103)$

\begin{tabular}{|l|c|c|c|c|c|c|}
\hline & Total $(\mathrm{n}=103)$ & Male (N) & Male with Mets & Female (N) & Female with Mets & Total Mets (M+F) \\
\hline Hypothyroid & $89(86 \%)$ & 24 & $5(20 \%)$ & 65 & $19(29 \%)$ & $24(27 \%)$ \\
\hline Hyperthyroid & $14(14 \%)$ & 7 & $1(14 \%)$ & 7 & $3(42 \%)$ & $4(28 \%)$ \\
\hline
\end{tabular}

\section{DISCUSSION}

Our results illustrate marked heterogeneity in the prevalence of Mets according to gender. Women (34.32\%: $\mathrm{p}<0.001$ ) had a significantly higher incidence of Mets as compared to men (14.12\%). This was also noted by khan and co. workers in their study of the urban population of India (2). Female predominance was also seen in a rural population of central India between the age group 18-50 years as reported by Kamble et al., in 2010 (3). Other studies done in India have shown an increased prevalence 
among males as compared to females (4). The BMC public health report of 2017 has shown a male predominance in the rural population and a female predominance in the urban population (5). The worldwide prevalence of Mets as reported by Carnier et al., varied from 8-43\% in men and 7 to $56 \%$ in women (6).

In NHANES III data the prevalence differed little among males (24.0\%) and female (23.40\%) (7). Other studies from China (8) and South Korea (9) have shown Mets to have a higher prevalence in women at age 50 years and surpassed men thereafter. Such differences have been attributed to the more stringent cut-off for waist circumference and HDL in women.

The prevalence of Mets also increased with age in both sexes. Ford and co-workers (10) in their study on the US adult population reported $10 \%$ in individuals aged $20-40$ and $45 \%$ in individuals aged $60-69$. This is in line with our incidence of $17 \%$ in individuals aged 2029 years and $21 \%$ in individuals aged $40-49 \%$ and 40 $\%$ in those aged 60-69 years. The overall percentage in our study was higher (23.5\%). Many cross-sectional studies have reported a high prevalence of Mets amongst postmenopausal women which varied from $32.6 \%$ to $41.5 \%(11,12)$. In the present study, $50.8 \%$ of women in the postmenopausal age group had Mets. In postmenopausal women, Prasad et al., (11) noted more than $60 \%$ MetS in subjects with age greater than 50 years compared to $6.7 \%$ in subjects of the age group 20-29 years. The increased prevalence of Mets among older adults may be explained by an increased sedentary lifestyle and functional disability and a decrease in physical activity. The metabolic changes accompanying menopause might explain the increased prevalence of Mets in this group.

The results showed a mean BMI of $24 \pm 4$ for both males and females. Sawant et al., in 2011 (13) had reported a mean BMI of $25.68 \%$ in males and $26.95 \%$ in females. The development of central obesity or more specifically an increase in abdominal fat is a primary event in the progression of Mets and is more prevalent among Asian Indians. Central obesity, the most frequently observed component of Mets is an independent risk factor for cardiovascular diseases (14).

The differences were analysed in Mets prevalence with an emphasis on employment type and socioeconomic factors. Current study findings indicate that unemployed participants and housewives were more likely to have MetS compared to those who were employed. This is consistent with the results of a study which suggests that employment pattern is an important risk factor in the development of Mets especially in females (15). Our study supports the statement that the reduced physical activity and excess energy intake in housewives are strongly associated with obesity which in turn plays a key role in the development of Mets (16). In the present study, Mets were significantly more prevalent in subjects of the APL group as compared to the BPL subgroup. Higher incidence of overweight and obesity observed in the upper-income group compared to the lower and middle-income group can be the reason for this increased prevalence. Prasad et al., (11) have further stated that socioeconomic status has emerged as an independent risk predictor for Mets. In the present study, the population diet did not significantly affect the prevalence of Mets.

All the individual components of Mets increased with age and higher prevalence was seen between the age of 50 to 59 years. In our study elevated blood sugar was a common abnormality observed and elevated blood pressure was the least common. in contrast, Prasad et al., (11) have reported elevated BP as the most common abnormality and elevated blood sugar the least. Low HDL (99.9\%) was a common abnormality amongst women and the least common abnormality amongst males (10\%). The prevalence of low HDL amongst Asian Indians has been validated by various studies (17)(18). Low HDL is a strong predictor of MI and stroke and is strongly associated with wish CAD. Obesity, a significant risk factor for various chronic diseases, is universally related to reduces HDL levels (19). Interestingly $62 \%$ of women in this study had elevated WC indicating that central obesity may be a contributing factor for low HDL in women. Increased fasting blood glucose and hypertriglyceridemia higher in males compared to females and were in line with the proven trends globally. It is well known that insulin resistance causes dyslipidaemia which includes increased TG synthesis and storage (20).

In our study, the overall prevalence of diabetes associated with Mets was $47.8 \%$ and that of IFG $42.2 \%$. This was higher in females as compared to males. The risk of diabetes has shown to increase with the number of Mets components (21). Earlier studies reported that among subjects with the same number of Mets components, combinations of WC and IFG seemed to be strongly associated with risk of developing type 2 diabetes mellitus (22).

\section{Thyroid state and metabolic syndrome}

In our study, $16 \%$ of the patients with Mets who were diagnosed with thyroid dysfunction were females predominantly of age greater than $40 \mathrm{yrs}$. This is in agreement with the results of other studies from India reporting an increased prevalence of Mets in hypothyroid subjects with an increasing tendency with age (23).

Mets is closely related with thyroid dysfunction due to the effect of thyroid hormones on obesity, lipid and glucose metabolism, hypertension, insulin resistance (IR) and cardiovascular events. Mets and hypothyroidism are characterized by a combination of common metabolic abnormalities such as obesity, 
hyperglycaemia, hypertension, reduced HDL cholesterol and elevated triglycerides (23). Moreover, IR, identified to have a greater impact on Mets, also plays a pivotal role in the development of hypothyroidism (24). The predominance of elevated TSH also suggests that Mets could also be a consequence of altered thyroid function during the natural course of the disease. The simultaneous occurrence of insulin resistance and obesity is the most detrimental for metabolic health indicating a possible interplay between thyroid status and Mets.

The current study population appear restricted in size and study region; consequently, it may underestimate or overestimate the true frequency of Mets in general population. Furthermore, the Measurement of free thyroxine would have added further information on the subject's thyroid status.

\section{CONCLUSION}

The prevalence of Mets was more than 23\%, and the prevalence was significantly higher in females. This gender-wise prevalence was noted across different age groups the maximum number of cases with Mets was in the age range greater than 40 years. interestingly a point to note was that the prevalence in the less than 40 age group was $14 \%$. In the subset of Mets patients, elevated waist circumference and low HDL was significantly higher among females. Hyperglycaemia and elevated levels of TG was significantly higher in the male population. Our study also shows that Mets is also associated with comorbidities such as impaired fasting glucose, diabetes mellitus and thyroid dysfunction. Early screening and identification and treatment of individuals with Mets may reduce morbidity and mortality in the elderly. Educational and interventional programs emphasizing lifestyle changes and weight reduction particularly in the less than 40 years' age group may help prevent the progression of MetS components like hypertension and central obesity.

\section{CONFLICT OF INTEREST}

Authors declare that there is no conflict of interest for this study.

\section{REFERENCES}

1. https://www.nhlbi.nih.gov/files/docs/guidelines/atglance.pdf

2. Khan, Y., Lalchandani, A., Gupta, A. C., Khadanga, S., Kumar, S. Prevalence of metabolic syndrome crossing $40 \%$ in Northern India: Time to act fast before it runs out of proportions. Journal of family medicine and primary care. 2018 Jan; 7(1): 118.

3. Kamble, P., Deshmukh, P. R., Garg, N. Metabolic syndrome in adult population of rural Wardha, central India. The Indian journal of medical research. 2010 Dec; 132(6): 701.

4. Harikrishnan, S., Sarma, S., Sanjay, G., Jeemon, P., Krishnan, M. N., Venugopal, K., et al., Prevalence of metabolic syndrome and its risk factors in Kerala, South India: Analysis of a community based cross-sectional study. PLoS One. 2018 Mar 27; 13(3): e0192372.

5. Ranasinghe, P., Mathangasinghe, Y., Jayawardena, R., Hills, A.P., Misra, A. Prevalence and trends of metabolic syndrome among adults in the asia-pacific region: a systematic review. BMC public health. 2017 Dec; 17(1): 1-9.

6. Cornier, M. A., Dabelea, D., Hernandez, T. L., Lindstrom, R. C., Steig, A. J., Stob N. R., et al., The metabolic syndrome. Endocrine reviews. 2008 Dec 1; 29(7): 777-822.

7. Hollenbeak, C., Spackman, E., Page, M. J., Ben-Joseph, R., Williamson, T. The Prevalence of Metabolic Syndrome in an NHANES Population. Blood. 2005; 106(11).

8. Huang, J., Huang, J. L., Withers, M., Chien, K. L., Trihandini, I., Elcarte, E., et al., Prevalence of metabolic syndrome in Chinese women and men: a systematic review and metaanalysis of data from 734511 individuals. The Lancet. 2018 Oct 1; 392: S14.

9. Lim, S., Shin, H., Song, J. H., Kwak, S. H., Kang, S. M., Yoon, J. W., et al., Increasing prevalence of metabolic syndrome in Korea: the Korean National Health and Nutrition Examination Survey for 1998-2007. Diabetes care. 2011 Jun 1; 34(6): 1323-1328.

10. Ford, E. S., Giles, W. H., Mokdad, A. H. Increasing prevalence of the metabolic syndrome among US adults. Diabetes care. 2004 Oct 1; 27(10): 2444-2449.

11. Prasad, D. S., Kabir, Z., Dash, A. K., Das, B. C. Prevalence and risk factors for metabolic syndrome in Asian Indians: A community study from urban Eastern India. Journal of cardiovascular disease research. 2012 Jul 1; 3(3): 204-211.

12. Chedraui, P., Hidalgo, L,, Chavez, D., Morocho, N., Alvarado, M., Huc, A. Quality of life among postmenopausal Ecuadorian women participating in a metabolic syndrome screening program. Maturitas. 2007 Jan 20; 56(1): 45-53.

13. Sawant, A., Mankeshwar, R, Shah, S., Raghavan, R., Dhongde, G., Raje H., et al., Prevalence of metabolic syndrome in urban India. Cholesterol. 2011; 2011.

14. Poirier, P., Giles, T. D., Bray, G. A., Hong, Y., Stern, J. S., et al., Obesity and cardiovascular disease: pathophysiology, evaluation, and effect of weight loss: an update of the 1997 American Heart Association Scientific Statement on Obesity and Heart Disease from the Obesity Committee of the Council on Nutrition, Physical Activity, and Metabolism. Circulation. 2006 Feb 14; 113(6): 898-918.

15. Mohamed, H. J., Mitra, A. K., Zainuddin, L. R., Leng, S. K., Muda, W. M. W., Women are at a higher risk of metabolic syndrome in rural Malaysia. Women and health. 2013 May 1; 53(4): 335-348.

16. Saboo, B., Talaviya, P., Chandarana, H., Shah, S., Vyas, C., Nayak, H. Prevalence of obesity and overweight in housewives and its relation with household activities and socio-economical status. Journal of Obesity and Metabolic Research. 2014 Jan 1; 1(1): 20.

17. Jesmin, S., Islam, M. R., Islam, A. S., Mia, M. S., Sultana, S. N., Zaedi, S., et al., Comprehensive assessment of metabolic syndrome among rural Bangladeshi women. BMC Public Health. 2012 Dec; 12(1): 1-1

18. Lucke-Wold, B., Misra, R., Patel, T. G. Risk factors for low high-density lipoprotein among Asian Indians in the United States. World Journal of Diabetes. 2017 Jun 15; 8(6): 297.

19. Wang, H., Peng, D. Q. New insights into the mechanism of low high-density lipoprotein cholesterol in obesity. Lipids in health and disease. 2011 Dec; 10(1): 1-0.

20. Al-Mahmood, A. K., Afrin, S. F., Hoque, N. Dyslipidemia in insulin resistance: cause or effect. Bangladesh Journal of Medical Biochemistry. 2014 Apr 11; 7(1): 27-31.

21. Lee, M. K., Han, K., Kim, M. K., Koh, E. S., Kim, E. S., Nam, G. E., et al., Changes in metabolic syndrome and its components and the risk of type 2 diabetes: a nationwide cohort study. Sci Rep [Internet]. 2020; 10(1): 1-8. Available from: http://dx.doi.org/10.1038/s41598-020-59203-z.

22. Kurotani, K., Miyamoto, T., Kochi, T., Eguchi, M., Imai, T., Nishihara, A., et al., Metabolic syndrome components and diabetes incidence according to the presence or absence of impaired fasting glucose: The Japan Epidemiology Collaboration on Occupational Health Study. Journal of epidemiology. 2017; 27(9): 408-412.

23. Deshmukh, V., Farishta, F., Bhole, M. Thyroid dysfunction 
in patients with metabolic syndrome: a cross-sectional, epidemiological, Pan-India study. International journal of endocrinology. 2018 Dec 25; 2018.

24. Chang, C. H., Yeh, Y. C., Caffrey, J. L., Shih, S. R., Chuang, L. M., et al., Metabolic syndrome is associated with an increased incidence of subclinical hypothyroidism-A Cohort Study. Scientific reports. 2017 Jul 28;7(1): 1-8. 